\title{
Health IT-Enabled Care Coordination: A National Survey of Patient-Centered Medical Home Clinicians
}

Suzanne Morton, MPH, MBA

Sarab C. Shib, MPH ${ }^{2}$

Chloe H. Winther, BA ${ }^{3}$

Aldo Tinoco, $M D, M P H, M S^{4}$

Rodger S. Kessler, $\mathrm{PbD}^{5}$

Sarab Hudson Scholle, MPH, DrPH

${ }^{1}$ National Committee for Quality Assurance, Washington, DC

${ }^{2}$ Primary Care Information Project, New York City Department of Health and Mental Hygiene, New York, New York

${ }^{3}$ University of Washington, Seattle, Washington

${ }^{4}$ Evolent Health, Arlington, Virginia

${ }^{5}$ University of Vermont College of Medicine, Burlington, Vermont

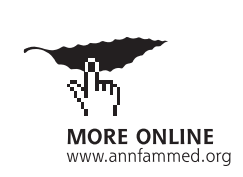

Conflicts of interest: Dr Scholle and Ms Morton are employed by the National Committee for Quality Assurance (NCQA), a not-for-profit organization that recognizes patient-centered medical homes. Dr Tinoco was also employed by NCQA at the time of this study. Dr Kessler, Ms Shib, and Ms Winther bave no conflicts of interest.

\section{CORRESPONDING AUTHOR}

Suzanne Morton, MPH, MBA

National Committee for Quality Assurance 1100 13th St NW, Ste 1000

Washington, DC 20005

morton@ncqa.org

\begin{abstract}
PURPOSE Health information technology (IT) offers promising tools for improving care coordination. We assessed the feasibility and acceptability of 6 proposed care coordination objectives for stage 3 of the Centers for Medicare and Medicaid Services electronic health record incentive program (Meaningful Use) related to referrals, notification of care from other facilities, patient clinical summaries, and patient dashboards.
\end{abstract}

METHODS We surveyed physician-owned and hospital/health system-affiliated primary care practices that achieved patient-centered medical home recognition and participated in the Meaningful Use program, and community health clinics with patient-centered medical home recognition (most with certified electronic health record systems). The response rate was $35.1 \%$. We ascertained whether practices had implemented proposed objectives and perceptions of their importance. We analyzed the association of organizational and contextual factors with self-reported use of health IT to support care coordination activities.

RESULTS Although $78 \%$ of the 350 respondents viewed timely notification of hospital discharges as very important, only $48.7 \%$ used health IT systems to accomplish this task. The activity most frequently supported by health IT was providing clinical summaries to patients, in $76.6 \%$ of practices; however, merely $47.7 \%$ considered this activity very important. Greater use of health IT to support care coordination activities was positively associated with the presence of a nonclinician responsible for care coordination and the practice's capacity for systematic change.

CONCLUSIONS Even among practices having a strong commitment to the medical home model, the use of health IT to support care coordination objectives is not consistent. Health IT capabilities are not currently aligned with clinicians' priorities. Many practices will need financial and technical assistance for health IT to enhance care coordination.

Ann Fam Med 2015;13:250-256. doi: 10.1370/afm.1797.

\section{INTRODUCTION}

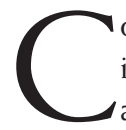
oordinating patient care is important for several reasons including the delivery of consistent guidance and recommendations, avoidance of unnecessary and/or duplicative testing, and ensuring timely access to services. A recent national survey showed that onethird of patients reported experiencing a gap in exchange of information between health care professionals involved in their care or between themselves and their health care professionals. ${ }^{1}$

Electronic health records (EHRs) and other health information technology (IT) offer the promise of making information sharing easier. ${ }^{2}$ Existing research shows infrequent use of health IT for care coordination, however. ${ }^{3,4}$ Even in settings where use of health IT is widespread, connectivity with other practices or facilities can be difficult. ${ }^{3}$ Beyond the technical challenges to information sharing, other factors such as internal workflows and lack of reimbursement for care coordination can limit successful use of health IT for care coordination. $2,5,6$ 
Implementing some aspects of care coordination is an expectation for clinicians who participate in the Centers for Medicare and Medicaid Services EHR incentive program for "meaningful use" of health IT (commonly known as the Meaningful Use or MU program). Although thousands of primary care clinicians have participated in this incentive program, adoption of the optional care coordination objectives is limited. For example, only $16 \%$ of clinicians reported that they sent a summary of care record for more than one-half of transitions of care and referrals. ${ }^{4}$

In future stages, the MU program will require practices to demonstrate more robust use of health IT for care coordination and in particular for exchange of information across settings of care. With designated funding from the Agency for Healthcare Research and Quality intended to inform federal policy making, we assessed the feasibility and acceptability of the care coordination objectives originally proposed for stage 3 of the MU program. Our specific research questions were (1) How frequently are electronic systems used for proposed MU stage 3 care coordination objectives? (2) How do clinicians view the importance of using health IT to support care coordination? and (3) What organizational and contextual factors are associated with greater use of health IT for care coordination?

\section{METHODS}

\section{Overview}

To find practices likely to be at the forefront of this developing area, we sampled practices recognized under the National Committee for Quality Assurance (NCQA) 2011 Patient-Centered Medical Home $(\mathrm{PCMH})$ program. We stratified our sample by practice type: practices owned by hospitals, health systems, or health plans; small physician-owned practices, with fewer than 5 full-time equivalent clinicians; larger physician-owned practices, with 5 or more full-time equivalent clinicians; and community health centers (CHCs), including both federally qualified health centers and others. For the first 3 groups, we limited the sample to practices having at least 1 clinician who had attested to the CMS Medicare EHR Incentive Program by September 2013. ${ }^{7}$ Because information on participation in Medicaid EHR incentive programs was not available, all $\mathrm{CHCs}$ were included. As $85 \%$ of $\mathrm{CHCs}$ had implemented an EHR certified by the Office of the National Coordinator for Health IT, and had completed a security risk analysis, most had the capability to perform all MU stage 1 objectives. We therefore believe that most of these $\mathrm{CHCs}$ were participating or considering participation in the MU program.
We sampled 1,000 of the 1,636 eligible practices. The final sample included 275 CHCs, 284 health system-owned practices, 247 small physician-owned practices, and 191 large physician-owned practices; 3 practices were ineligible at the end of the study. In each practice, we randomly chose a clinician who had attested to the $\mathrm{MU}$ program $i$ for $\mathrm{CHCs}$, we randomly selected any clinician.

We surveyed clinicians between January and July 2014, using web-based questionnaires as well as fax and mail methods. Practices received a $\$ 50$ gift basket for participation. The study protocol was reviewed and determined exempt by Chesapeake Research Review Inc, an independent institutional review board.

\section{Survey and Data Collection Instruments}

\section{Care Coordination Activities}

We adapted questions from the National Ambulatory Medical Care Survey ${ }^{8}$ to ask about 6 objectives originally proposed for MU stage 3 in the fall of 2012 including steps in referral coordination with other providers, notification of care received in emergency departments (EDs) and hospitals, provision of clinical summaries to patients, and use of patient dashboards (Table 1). ${ }^{9}$ The items were pretested with several clinicians not included in the study sample. For each care coordination activity, we asked clinicians to report on whether the practice performed the activity routinely and whether it routinely used an electronic system (health IT) for that activity. We also asked whether the

\section{Table 1. Care Coordination Activities Originally Proposed as Objectives for Stage 3 of the Meaningful Use Program ${ }^{9}$}

1. The clinical summary for patients should be pertinent to the office visit, not just an abstract from the medical record.

2. Use computerized provider order entry for referrals/transition of care orders.

3. Provide a summary of care record for each site transition or referral when transition or referral occurs with available information.

4. Provider receiving referral acknowledges receipt of external information and provides referral results to the requesting provider, thereby beginning to close the loop.

5. Electronic notification of a significant health care event in a timely manner to key members of the patient's care team (significant event $=$ arrival at an emergency department, admission to a hospital, discharge from an emergency department or hospital, or death)

6. Generate lists of patients for multiple specific conditions and present near real-time patient-oriented dashboards.

Note: The final list of proposed care coordination objectives that was submitted for consideration to the Office of the National Coordinator for Health Information Technology was updated and differs from this original list. The 3 referral-related objectives were merged under a single objective. Additionally, the objective that contained "real-time patient-oriented dashboards" was not included in the final list. (Source: HITPC Meaningful Use Stage 3 Final Recommendations. Office of the National Coordinator for Health Information Technology. http://www.healthit.gov/sites/faca/files/HITPC_MUWG_Stage3_Recs_201404-01.pdf. Published Apr 1, 2014. Accessed Mar 15, 2015.) 
practice had remote access to their patients' medical records. We summarized these reports using an index that captured the number of care coordination activities performed routinely ( 0 to 10 activities included within the 6 MU objectives). We dichotomized this care coordination index to compare practices performing all 10 activities with those performing fewer. We also created a health IT-enabled care coordination index (health IT index) by summing the number of care coordination activities performed with health IT support (treated as a continuous variable, 0 to 10 of the activities).

\section{Organizational and Contextual Factors}

We used Solberg's conceptual model for improving practices ${ }^{10}$ to identify factors that might affect implementation of care coordination using health IT. Organizational factors included level of PCMH 2011 recognition (Level 3, requiring 85 out of 100 possible points vs Level 1 or 2), ${ }_{1}^{11}$ practice type, and practice location (urban, suburban, or rural). Clinicians reported on whether there was a nonclinician specifically responsible for care coordination in the practice. In addition, they characterized the financial health of their practice. ${ }^{12}$

Contextual factors included whether the practices had participated in a PCMH demonstration program or pilot project, whether they had received payment for being a PCMH, and whether they had received consultation or participated in a learning collaborative addressing care coordination. We used the Strategies scale of the Change Process Capability Questionnaire (CPCQ) of Solberg et a ${ }^{13}$ to assess practices' use of techniques such as rapid-cycle testing and involvement of staff and patients in quality improvement. Each of the 17 scale items was rated "yes, worked well" (1 point), "yes, did not work well" (1/2 point), and "no" (0 points). We summed the results to get a score on a scale of 0 to 17 points; higher scores indicate greater capability to undertake change. Clinicians also reported on the level of priority within the practice for both care coordination and implementing MU requirements on a scale of 0 to 10 points. ${ }^{13}$

\section{Attitudes About Care Coordination}

Clinicians rated the importance of having health IT support for care coordination objectives on a 5 -point scale, with 5 being "very important." They also reported on potential challenges to care coordination using a 5 -point scale, with 5 being a "major barrier."

\section{Analysis}

We present descriptive analyses for key variables. For continuous variables, we imputed values based on the mean of the practice type from which they were sampled. We used $\chi^{2}$ tests and multivariate logistic and linear regression analyses to test the associations of independent variables with the care coordination index and the health IT index, respectively. The final regression models predicting these indices included the level of financial concern, whether a nonclinician was in charge of care coordination, the CPCQ Strategies score, and help for care coordination (through consultation or a learning collaborative). The model for care coordination also included PCMH level and geography. The following variables were dropped after showing no effect in the initial regression analyses: priority for care coordination, priority for implementing $\mathrm{MU}$ objectives, and participation in a demonstration project or payment for being a PCMH. The analyses were performed using SAS software, version 9.4 (SAS Institute Inc).

\section{RESULTS}

\section{Practice Characteristics}

Of the 997 practices invited to participate, 350 (35.1\%) responded. There were no response differences by practice type, specialty, region of the country, or participation in earlier versions of NCQA PCMH recognition. Clinicians from practices with Level $3 \mathrm{PCMH}$ 2011 recognition were more likely to respond (37.3\% for Level 3 vs 29.4\% for Level 1 or 2).

Most respondents were from practices with Level 3 PCMH recognition (Table 2). Clinicians practiced in 41 states and were from diverse geographic areas. Approximately one-third of clinicians were very concerned about the financial condition of their practice. More than $76 \%$ of practices received help for care coordination improvement. More than $58 \%$ of clinicians reported their practice had a nonclinician specifically responsible for care coordination.

\section{Care Coordination Activities and Use of Health IT for Activities}

Nearly all clinicians reported that their practice routinely sends referral requests (92.3\%) and responds to information requests from clinicians receiving referrals (90.0\%) (Table 3). Fewer clinicians reported routine tracking of referrals until a report comes back from the consulting clinician $(57.4 \%$ for nonurgent referrals and $68.6 \%$ for urgent referrals) and identifying ED visits by their patients $(63.1 \%)$. Clinicians from health system practices reported their practices were less likely to track routine referrals, and clinicians from $\mathrm{CHCs}$ reported less frequent identification of hospitalizations.

The care coordination activities most routinely implemented were not the ones with the greatest degree of health IT support. The use of electronic systems for individual care coordination activities ranged from $38.8 \%$ for identifying patients with an ED visit to $76.6 \%$ for providing clinical summaries to patients. 
There were few differences in the use of electronic systems for care coordination by practice type.

Overall, 21.1\% of clinicians reported that their practices performed all 10 care coordination activities and on average conducted 6 of 10 activities using health IT systems (Table 4). Regression analyses showed that support for care coordination, geographic location, having a nonclinician responsible for care coordination,
Table 2. Characteristics of Participating Practices $(\mathrm{N}=350)$

\begin{tabular}{|c|c|c|c|}
\hline Characteristic & $\begin{array}{c}\text { Practices, } \\
\%\end{array}$ & Characteristic & $\begin{array}{c}\text { Practices, } \\
\%\end{array}$ \\
\hline \multirow{4}{*}{$\begin{array}{l}\text { PCMH level: Level } 3 \\
\text { Practice type } \\
\text { Community health center } \\
\text { Health system-owned } \\
\text { practice }\end{array}$} & 76.9 & $\begin{array}{l}\text { Demonstration/pilot project par- } \\
\text { ticipation and PCMH payment }\end{array}$ & \\
\hline & \multirow{2}{*}{26.0} & Both & 46.0 \\
\hline & & Demonstration/pilot project only & 16.6 \\
\hline & 26.3 & Payment for $\mathrm{PCMH}$ only & 17.1 \\
\hline \multirow{2}{*}{$\begin{array}{l}\text { Physician-owned, <5 FTE } \\
\text { clinicians }\end{array}$} & \multirow{2}{*}{25.1} & Neither & \multirow[t]{2}{*}{20.3} \\
\hline & & Type of area & \\
\hline $\begin{array}{l}\text { Physician-owned, } \geq 5 \text { FTE } \\
\text { clinicians }\end{array}$ & 22.6 & \multirow{3}{*}{$\begin{array}{l}\text { Urban } \\
\text { Suburban } \\
\text { Rural }\end{array}$} & 28.3 \\
\hline \multirow{2}{*}{$\begin{array}{l}\text { Financial concern: very con- } \\
\text { cerned }(N=345)\end{array}$} & \multirow{2}{*}{34.2} & & 45.1 \\
\hline & & & 26.6 \\
\hline \multicolumn{2}{|l|}{ EHR system vendor $(\mathrm{N}=343)$} & \multirow{3}{*}{$\begin{array}{l}\text { Received consultation/collabora- } \\
\text { tion help for care coordination } \\
(\mathrm{N}=336)\end{array}$} & \multirow{3}{*}{76.5} \\
\hline eClinicalWorks & 20.7 & & \\
\hline Allscripts & 14.6 & & \\
\hline NextGen & 14.0 & Characteristic & Mean (SD) \\
\hline Epic & 13.4 & Priority for Care Coordination score ${ }^{a}$ & $6.7(2.2)$ \\
\hline GE/Centricity & 7.0 & Priority for Implementing Mean- & $75(20)$ \\
\hline Other & 30.3 & ingful Use score ${ }^{a}$ & $1.5(2.0)$ \\
\hline $\begin{array}{l}\text { Have a nonclinician in charge } \\
\text { of care coordination }\end{array}$ & 58.3 & $\begin{array}{l}\text { Change Process Capability Ques- } \\
\text { tionnaire, Strategies scale score }\end{array}$ & $10.2(3.9)$ \\
\hline $\begin{array}{l}\mathrm{EHR}=\text { electronic health record; } \mathrm{F} \\
\text { cal home. }\end{array}$ & full-time equ & tt; GE = General Electric; PCMH = patie & ntered medi- \\
\hline a On a scale of 0 to 10 points. Hig & scores indicate & greater perceived priority. & \\
\hline${ }^{\mathrm{b}}$ On a scale of 0 to 17 points. Hig & r scores indicate & reater capability to undertake change. & \\
\hline
\end{tabular}

Table 3. Routine Performance of Care Coordination Activities in Practices $(\mathrm{N}=350)$

\begin{tabular}{|c|c|c|}
\hline \multirow[b]{2}{*}{ Care Coordination Activity } & \multicolumn{2}{|c|}{ Practices, \% } \\
\hline & $\begin{array}{l}\text { Routinely } \\
\text { Perform } \\
\text { Activity }\end{array}$ & $\begin{array}{l}\text { Routinely Use } \\
\text { Health IT to } \\
\text { Perform Activity }\end{array}$ \\
\hline 1. Provide patients with clinical summaries of their visits & 81.4 & 76.6 \\
\hline 2. Send referral requests to other clinicians & 92.3 & 68.6 \\
\hline $\begin{array}{l}\text { 3. Provide a comprehensive medical summary for each site } \\
\text { transition or referral }\end{array}$ & 69.4 & 45.4 \\
\hline $\begin{array}{l}\text { 4. Respond to requests for additional information from clini- } \\
\text { cian receiving referral }\end{array}$ & 90.0 & 54.0 \\
\hline $\begin{array}{l}\text { 5. Provider receiving referral provides referral results to the } \\
\text { requesting provider }\end{array}$ & 82.0 & $53.4^{a}$ \\
\hline $\begin{array}{l}\text { 6. Provide reminders for guideline-based interventions or } \\
\text { screening tests to clinicians at the point of care }\end{array}$ & 74.3 & 64.9 \\
\hline 7. Identify patients who have had an emergency department visit & 63.1 & 39.4 \\
\hline 8. Identify patients who have had a hospital admission/discharge & $75.4^{\mathrm{a}}$ & 48.9 \\
\hline 9. Have a system for remote access to patient's medical record & $\mathrm{n} / \mathrm{a}$ & 80.9 \\
\hline 10. Track referrals & & 51.7 \\
\hline Track urgent referrals until results or report come back & $68.6^{a}$ & \\
\hline Track nonurgent referrals until results or report come back & 57.4 & \\
\hline
\end{tabular}

and having a stronger capacity to change (based on the CPCQ Strategies score) were associated with greater implementation of care coordination activities. Concern about the practice's financial health was related to lower implementation of care coordination activities A higher CPCQ Strategies score $(P<.001)$ and having a nonclinician responsible for care coordination $(P=.01)$ were also significantly associated with greater use of health IT to perform care coordination.

\section{Importance of Health IT for Care Coordination and Barriers}

Clinicians gave the highest importance ratings to timely electronic notification of hospital discharges $(77.5 \%$ rated it as "very important") and patient deaths (73.0\%) (Table 5). The least-valued objectives were specialist acknowledgment of patient information (32.9\%) and real-time patient dashboards (40.1\%). The greatest barriers to coordinating patient care with other practices or facilities were time $(39.9 \%$ rated it as a major barrier), money and other resources $(35.1 \%)$, and IT/EHR systems (32.1\%).

Additional tables showing the results for different practice types are included in the Supplemental Appendixes, available at http://www.annfammed.org/ content/13/3/250/suppl/DC1.

\section{DISCUSSION}

\section{Key Findings}

Our findings show that $\mathrm{PCMH}$ practices still depend on nonhealth IT methods to manage 
Table 4. Associations of Practice Characteristics With Care Coordination Activities and Health IT Use

\begin{tabular}{|c|c|c|c|c|c|}
\hline \multirow[b]{2}{*}{ Characteristic } & \multicolumn{2}{|c|}{$\begin{array}{l}\text { Performance of All } 10 \text { Care } \\
\text { Coordination Activities }\end{array}$} & \multicolumn{2}{|c|}{$\begin{array}{c}\text { Use of Health IT for Care } \\
\text { Coordination (Health IT } \\
\text { Index) }\end{array}$} & \multirow[b]{2}{*}{$P$ Value } \\
\hline & $\begin{array}{l}\text { Practices, \%a } \\
(\mathrm{N}=350)\end{array}$ & $\begin{array}{l}\text { OR }(95 \% \mathrm{Cl})^{\mathrm{b}} \\
(\mathrm{N}=332)\end{array}$ & $\begin{array}{l}\text { Mean Scorec } \\
(\mathrm{N}=350)\end{array}$ & $\begin{array}{l}\beta \text { Coefficient }^{\mathrm{b}} \\
(\mathrm{N}=332)\end{array}$ & \\
\hline Overall & 21.1 & - & 5.8 & - & - \\
\hline \multicolumn{6}{|l|}{ Practice type, } \\
\hline Community health centers & 18.7 & $1.6(0.8-3.8)$ & 5.4 & -0.3 & .41 \\
\hline Health system owned & 16.3 & Ref & 5.9 & Ref & \\
\hline Physician owned, <5 FTE clinicians & 25.0 & $1.7(0.9-3.9)$ & 6.1 & 0.3 & .45 \\
\hline Physician owned, $\geq 5$ FTE clinicians & 25.3 & $1.5(0.7-3.4)$ & 6.0 & -0.1 & .80 \\
\hline \multicolumn{6}{|l|}{ PCMH level } \\
\hline Level 1 or 2 & 16.1 & Ref & 5.4 & $\mathrm{n} / \mathrm{a}$ & $\mathrm{n} / \mathrm{a}$ \\
\hline Level 3 & 22.7 & $1.6(0.7-3.4)$ & 6.0 & $\mathrm{n} / \mathrm{a}$ & $\mathrm{n} / \mathrm{a}$ \\
\hline \multicolumn{6}{|l|}{ Financial concern } \\
\hline Less than very concerned & 23.8 & Ref & 5.9 & Ref & $\mathrm{n} / \mathrm{a}$ \\
\hline Very concerned & 14.4 & $0.4(0.2-0.8)^{d}$ & 5.6 & -0.4 & .13 \\
\hline \multicolumn{6}{|l|}{$\begin{array}{l}\text { Have nonclinician in charge of care } \\
\text { coordination }\end{array}$} \\
\hline No & 14.4 & Ref & 5.3 & Ref & $\mathrm{n} / \mathrm{a}$ \\
\hline Yes & 26.0 & $1.9(1.0-3.5)^{d}$ & 6.2 & 0.7 & .01 \\
\hline \multicolumn{6}{|l|}{ Type of area } \\
\hline Urban & 12.1 & Ref & 5.5 & $\mathrm{n} / \mathrm{a}$ & $\mathrm{n} / \mathrm{a}$ \\
\hline Rural or suburban & 24.7 & $2.5(1.2-5.3)^{d}$ & 6.0 & $\mathrm{n} / \mathrm{a}$ & $\mathrm{n} / \mathrm{a}$ \\
\hline \multicolumn{6}{|l|}{$\begin{array}{l}\text { Received consultation/collaboration help } \\
\text { for care coordination }\end{array}$} \\
\hline No & 8.9 & Ref & 4.8 & Ref & $\mathrm{n} / \mathrm{a}$ \\
\hline Yes & 25.3 & $2.6(1.1-6.4)^{d}$ & 6.2 & 0.6 & .06 \\
\hline $\begin{array}{l}\text { Change Process Capability Questionnaire, } \\
\text { Strategies scale }\end{array}$ & $1.1(1.1-1.2)^{f}$ & $1.1(1.0-1.2)^{\mathrm{d}, \mathrm{f}}$ & 5.8 & 0.2 & $<.0001$ \\
\hline \multicolumn{6}{|c|}{$\begin{array}{l}\mathrm{FTE}=\text { full-time equivalent; IT = information technology (computerized system/electronic health record system); n/a = not applicable; } \mathrm{OR}=\text { odds ratio; } \mathrm{PCMH}=\text { patient- } \\
\text { centered medical home; Ref }=\text { Reference group. }\end{array}$} \\
\hline \multicolumn{6}{|l|}{ a Unadjusted. } \\
\hline \multicolumn{6}{|l|}{ b From multivariate regression analysis. } \\
\hline \multirow{2}{*}{\multicolumn{6}{|c|}{$\begin{array}{l}\text { ' Unadjusted; on a scale of } 0 \text { to } 10 \text {, where higher score indicates greater number of coordination activities performed with health IT. } \\
\text { d Statistically significant. }\end{array}$}} \\
\hline \multicolumn{5}{|l|}{ e On a scale of 0 to 17} & \\
\hline${ }^{f}$ For a 1-unit change in score. & & & & & \\
\hline
\end{tabular}

care coordination. Fewer than one-half of practices routinely used computerized systems to identify patients seen in EDs or hospitals or to send a comprehensive care summary to other providers; however, the use of health IT for care coordination in this study was higher than that seen in earlier national physician surveys. ${ }^{14,15}$ Our results show a greater proportion of clinicians routinely using a computerized system for tracking referrals $(51.7 \%)$ in comparison with an earlier study $(28.6 \%)_{i}$ similarly, our study had a greater proportion of respondents providing patients with clinical summaries (76.6\% vs $33.3 \%){ }^{15}$ The higher use in our study could reflect increased adoption of health IT over time or the fact that these practices were PCMHs.

A recent Health and Human Services report to the US Congress highlighted 3 available methods to exchange information electronically: directed, query based, and consumer mediated. ${ }^{16}$ Regardless of which method is implemented, however, clinicians on both ends of the exchange must use compatible methods and adopt them into routine workflow. A recent study showed that compared with primary care clinicians, specialists were less likely to use certain MU functions. ${ }^{15}$ In a companion site observation study, we visited practices that had EHR systems with electronic exchange capabilities; however, practices with these EHR capabilities routinely used secure e-mail or fax for most care coordination activities with outside physician offices and facilities (Tinoco et al, unpublished data, 2015).

Importantly, the use of computerized systems for supporting care coordination was not consistent with clinicians' priorities. Most respondents highly valued identifying patients who had been discharged from the hospital or died, yet these activities were least likely to 
be supported electronically. Conversely, clinical summaries were frequently generated by a computerized system but not highly valued by clinicians.

Care coordination is related to both internal characteristics of the practice and the external environment in which it operates. Practices with nonclinician staff specifically assigned to coordinate care and with a higher capability for systematic change were more likely to implement care coordination activities as well as conduct them electronically. This finding is consistent with prior work suggesting greater team cohesion supports effective use of an integrated EHR for care coordination. ${ }^{17}$

The practice environment is also important. Compared with urban practices, practices located in rural or suburban communities were more likely to implement care coordination activities. Another study reported that urban and suburban physicians have difficulty coordinating patient care because their patients belong to multiple medical systems. ${ }^{18}$

\section{Limitations}

By design, we sampled practices that were poised for implementation of $\mathrm{MU}$ stage 3 based on their adoption of $\mathrm{PCMH}$ and participation in MU stage 1. Our findings thus should represent a best-case scenario. Although the response rate of $35.1 \%$ was low, 2 recent studies suggest that lower responses rates among physicians are associated with little to no response bias. ${ }^{19,20}$ We also did not observe significant differences between respondents and nonrespondents for practice characteristics with the exception of PCMH level. This study relied on selfreport; therefore, we were not able to gain detailed information on the capabilities of electronic systems. The proposed MU stage 3 objectives have changed since we administered our survey ${ }^{21}$; however, the findings are relevant to the current state of care coordination in practices and can inform future policy, development of EHR capabilities, and their implementation in practices.

\section{Policy and Practice Implications}

Computerized systems often don't support the care coordination activities that clinicians value most. In this study, assistance from consultants or participation in a collaborative about care coordination had a positive impact on the performance of care coordination activities. To improve uptake of health IT for care coordination to meet clinicians' needs, practices will need technical assistance to help redesign workflows and enhance technologic capabilities. For other activities not highly valued by clinicians, such as using patient dashboards for population management, even greater technical assistance will likely be needed as well as education to highlight their benefits. ${ }^{22}$ Technical assistance can also facilitate the increased use of change management strategies, which influenced both the level of care coordination activity and electronic support for this activity.

One factor associated with greater use of health IT for care coordination was having a nonclinician responsible for care coordination. Dedicating staff to care coordination will require additional resources for many practices. Clinicians who were concerned about their practices' financial situation worked in practices that performed fewer care coordination activities. Our study also showed time and money or other resources were the greatest barriers to coordinating patient care with other practices or facilities. Reimbursement approaches that support non-visit-based care are critical to improving care coordination; examples include the new Medicare initiatives such as reimbursement for chronic care management services and a valuebased payment modifier. ${ }^{23,24}$

\section{Conclusions}

Practices vary in their capability to perform the proposed 
MU stage 3 objectives related to care coordination. Greater delegation to nonclinicians and improvements in systemic capacity for change may improve practices ability to perform care coordination activities with electronic support. Many practices will need additional technical and financial assistance to help implement new workflows and health IT systems to achieve this goal. Education can also increase clinicians' awareness about the benefits of those care coordination activities that they currently value less.

To read or post commentaries in response to this article, see it online at http://www.annfammed.org/content/13/3/250.

Key words: care coordination; electronic health records; meaningful use; patient-centered medical home; practice-based research; primary care; technology

Submitted December 23, 2014; submitted, revised, March 28, 2015; accepted April 5, 2015.

Funding support: This project was supported by grant number R18HS022693 from the Agency for Healthcare Research and Quality.

Previous presentations: Results of this study were presented at a national AHRQ Practice-Based Research Network Resource Center-sponsored webinar, Practical Insights on Meeting Objectives of Meaningful Use III, on January 28, 2015. An abstract about these survey results was also recently accepted for an oral presentation at the Academy Health Annual Research Meeting on June 14, 2015.

Disclaimer: The content is solely the responsibility of the authors and does not necessarily represent the official views of the AHRQ.

Supplementary materials: Available at http://www.AnnFamMed. org/content/13/3/250/suppl/DC1/.

\section{References}

1. Patel V, Barker W, Siminerio E. Individuals' Access and Use of their Online Medical Record Nationwide. Washington, DC: Office of the National Coordinator for Health Information Technology, 2014. ONC Data Brief, no. 20. http://www.healthit.gov/sites/default/files/ consumeraccessdatabrief_9_10_14.pdf. Accessed Mar 15, 2015.

2. O'Malley AS, Grossman JM, Cohen GR, Kemper NM, Pham HH. Are electronic medical records helpful for care coordination? Experiences of physician practices. J Gen Intern Med. 2010;25(3):177-185.

3. Furukawa MF, King J, Patel V, Hsiao CJ, Adler-Milstein J, Jha AK. Despite substantial progress in EHR adoption, health information exchange and patient engagement remain low in office settings. Health Aff (Millwood). 2014;33(9):1672-1679.

4. Wright A, Feblowitz J, Samal L, McCoy AB, Sittig DF. The Medicare Electronic Health Record Incentive Program: provider performance on core and menu measures. Health Serv Res. 2014;49(1 Pt 2):325-346.

5. Unertl KM, Johnson KB, Lorenzi NM. Health information exchange technology on the front lines of healthcare: workflow factors and patterns of use. J Am Med Inform Assoc. 2012;19(3):392-400.

6. Ross SE, Schilling LM, Fernald DH, Davidson AJ, West DR. Health information exchange in small-to-medium sized family medicine practices: motivators, barriers, and potential facilitators of adoption. Int J Med Inform. 2010;79(2):123-129.

7. Data and Program Reports. EP Recipients of Medicare EHR Incentive Program Payments. Centers for Medicare \& Medicaid Services website. http://www.cms.gov/Regulations-and-Guidance/Legislation/ EHRIncentivePrograms/DataAndReports.html. Accessed Nov 2013.
8. National Electronic Health Records Survey 2012. National Hospital Ambulatory Medical Care Survey. Centers for Disease Control and Prevention website. http://www.cdc.gov/nchs/data/ahcd/2012_EHR_ Survey.pdf. Accessed Mar 15, 2015.

9. Office of the National Coordinator for Health Information Technology; Health Information Technology. HIT Policy Committee: Request for Comment Regarding the Stage 3 Definition of Meaningful Use of Electronic Health Records (EHRs). Office of the National Coordinator for Health Information Technology website. http://www. healthit. gov/sites/default/files/hitpc_stage3_rfc_final.pdf. Published 2012. Accessed Mar 15, 2015.

10. Solberg LI. Improving medical practice: a conceptual framework. Ann Fam Med. 2007;5(3):251-256.

11. NCQA White Paper. NCQA's Patient-Centered Medical Home (PCMH) 2011. National Committee for Quality Assurance website. http:// www.ncqa.org/Portals/0/Newsroom/PCMH\%202011\%20White\%20 Paper_4.6.12.pdf. Published 2011. Accessed Mar 15, 2015.

12. Jaen $C R$, Crabtree BF, Palmer RF, et al. Methods for evaluating practice change toward a patient-centered medical home. Ann Fam Med. 2010;8(Suppl 1):S9-S20, S92.

13. Solberg LI, Asche SE, Margolis KL, Whitebird RR. Measuring an organization's ability to manage change: the change process capability questionnaire and its use for improving depression care. Am J Med Qual. 2008;23(3):193-200.

14. Hsiao C-J, Hing E. Centers for Disease Control and Prevention (CDC). National Center for Health Statistics. Use and characteristics of electronic health record systems among office-based physician practices: United States, 2001-2013. NCHS Data Brief No. 143. http://www.cdc. gov/nchs/data/databriefs/db143.pdf. Published Jan 2014. Accessed Apr 7, 2015.

15. DesRoches CM, Audet AM, Painter M, Donelan K. Meeting meaningful use criteria and managing patient populations: a national survey of practicing physicians. Ann Intern Med. 2013;158(11):791-799.

16. Report to Congress. Update on the adoption of health information technology and related efforts to facilitate the electronic use and exchange of health information. The Office of the National Coordinator for Health Information Technology website. http://www.healthit. gov/sites/default/files/rtc_adoption_and_exchange9302014.pdf. Published Oct 2014. Accessed Mar 22, 2015.

17. Graetz I, Reed M, Shortell SM, Rundall TG, Bellows J, Hsu J. The next step towards making use meaningful: electronic information exchange and care coordination across clinicians and delivery sites. Med Care. 2014;52(12):1037-1041.

18. Khoong EC, Gibbert W/S, Garbutt JM, Sumner W, Brownson RC. Rural, suburban, and urban differences in factors that impact physician adherence to clinical preventive service guidelines. J Rural Health. 2014;30(1):7-16.

19. Willis $G B$, Smith $T$, Lee HJ. Do additional recontacts to increase response rate improve physician survey data quality? Med Care. 2013;51(10):945-948.

20. Bjertnaes OA, Garratt A, Botten G. Nonresponse bias and costeffectiveness in a Norwegian survey of family physicians. Eval Health Prof. 2008;31(1):65-80.

21. HITPC Meaningful Use Stage 3 Final Recommendations. Office of the National Coordinator for Health Information Technology Website. http://www.healthit.gov/sites/faca/files/HITPC_MUWG_Stage3_ Recs_2014-04-01.pdf. Published Apr 1, 2014. Accessed Mar 15, 2015.

22. Jones SS, Rudin RS, Perry T, Shekelle PG. Health information technology: an updated systematic review with a focus on meaningful use. Ann Intern Med. 2014;160(1):48-54.

23. Edwards ST, Landon BE. Medicare's chronic care management payment-payment reform for primary care. N Engl J Med. 2014;371(22): 2049-2051.

24. Centers for Medicare and Medicaid Services. Value-Based Payment Modifier. http://www.cms.gov/Medicare/Medicare-Fee-for-ServicePayment/PhysicianFeedbackProgram/ValueBasedPaymentModifier. html. Updated Mar 26, 2015. Accessed Mar 27, 2015. 